\title{
The Effects of a Changing World of Work on Daily Working Life
}

\author{
Roman Prem \\ University of Vienna, Austria
}

This manuscript has been published as a chapter in the following edited book:

Korunka, C., \& Kubicek, B. (Eds.). (2017). Job demands in a changing world of work: Impact on workers' health and performance and implications for research and practice. Cham, Switzerland: Springer. https://doi.org/10.1007/978-3-319-54678-0_7

(C) 2017 Springer. This manuscript may not exactly replicate the authoritative document published in the edited book. It is not the copy of record.

\section{Author Note}

Correspondence should be addressed to Roman Prem, Department of Applied Psychology: Work, Education, Economy, Faculty of Psychology, University of Vienna, Universitätsstraße 7, 1010 Vienna, Austria. (e-mail: roman.prem@univie.ac.at).

\section{Author biography}

Roman Prem is a postdoctoral researcher at the University of Vienna, Austria, where he recently received his Ph.D. in Work and Organizational Psychology. His current research focuses on the role of cognitive appraisal and self-control in occupational stress processes. He is also interested in interactions between stress processes, motivational processes, and recovery processes as well as the antecedents of procrastination and proactive behavior at work. 


\begin{abstract}
This book chapter explores how changes in work environments due to societal, economic, and technological change may affect day-level within-person processes of action regulation, cognitive appraisal, and motivation. First, short overviews of action regulation theory (e.g., Frese \& Zapf, 1994), cognitive appraisal theories (e.g., Lazarus \& Folkman, 1984), and self-determination theory (Ryan \& Deci, 2000) are given and results of empirical diary studies based on these theories are discussed. On the basis of these theories, a framework model is presented that integrates action regulation processes, cognitive appraisal processes, and motivation processes in daily working life by focusing on their effects on self-control effort and learning at work. Next, possible effects of changing work environments on day-level withinperson processes are discussed on the basis of this framework model. It is argued that although some changes in work environments may have mainly adverse effects (e.g., work intensification), many changes hold the potential for both adverse and beneficial effects (e.g., flexible working). Based on the assumed potentially ambivalent consequences of changes in working conditions, implications for organizations and practitioners are discussed.
\end{abstract}

Keywords: changing work environments; within-person processes; action regulation; selfregulation; cognitive appraisal; challenge-hindrance; self-determination; motivation; selfcontrol effort; learning at work; thriving at work 


\section{The Effects of a Changing World of Work on Daily Working Life}

The world of work has changed considerably in recent decades as societal, economic, and technological changes driven by financialization, the network economy, and digitalization (see also Chapter 2) affect how work is structured and carried out (Cascio, 1995; Rosa, 2003, 2013). In modern work settings, employees are faced with new job demands, which drain their resources and threaten their well-being (e.g., Kubicek, Paškvan, \& Korunka, 2015). For example, work intensification puts additional demands on employees (see also Chapter 3) and in some cases job autonomy may even lose its beneficial effects and start to show its dark sides (see also Chapter 4). Further, a shift of responsibility for career management from organizations to employees themselves can also be considered a new demand. However, crafting one's career to be in line with one's goals (see also Chapter 5) and using forms of flexible work to satisfy one's psychological needs (see also Chapter 6) may also hold the potential for positive effects, as these aspects of modern work bring additional opportunities for growth, motivation, and learning. Overall, changing work environments appear to hold the potential for both adverse as well as beneficial effects on employees' well-being and performance in daily working life.

To explain how changes in modern work settings can affect daily working life, the present chapter will first give an overview of the state of research on the underlying mechanisms that link work characteristics to work outcomes. In particular, the present chapter will discuss the role of action regulation (e.g., Frese \& Zapf, 1994; Diestel \& Schmidt, 2012), cognitive appraisal (e.g., Lazarus \& Folkman, 1984; Searle \& Auton, 2015), and motivational processes (e.g., Ryan \& Deci, 2000; Gagné \& Deci, 2005) before integrating them into a framework model. Later on, I will discuss how changes in modern work settings might affect these withinperson processes of action regulation, cognitive appraisal, and motivation. Finally, the focus will shift to the potentially ambivalent consequences of changes in modern work environments for daily work outcomes. Both adverse (e.g., job strain, burnout, ego depletion, procrastination) 
and beneficial (proactivity, job engagement, well-being, and thriving at work) consequences will be considered.

\section{Linking Work Characteristics to Work Outcomes in Daily Working Life}

To obtain more thorough knowledge about the short-term processes through which work characteristics affect work outcomes, researchers in work and organizational psychology have increasingly turned to diary studies over the past few decades (cf. Fisher \& To, 2012; Ohly, Sonnentag, Niessen, \& Zapf, 2010). In contrast to cross-sectional studies that only allow researchers to analyze their data and interpret their results at the inter-individual or betweenperson level, diary studies enable researchers to investigate phenomena and processes at the intra-individual or within-person level.

Diary studies usually require participants to fill out short questionnaires once or even several times per workday over a period of one or more work weeks (e.g., Ohly et al., 2010). At each measurement occasion, participants may be asked to indicate their daily job demands and job resources and/or their momentary thoughts, feelings, and behaviors in naturalistic work settings. By "capturing life as it is lived" (Bolger, Davis, \& Rafaeli, 2003, p. 579), diary methods reduce the probability of bias due to recall and retrospection that often arises in questionnaires. Even more importantly, repeating measures within comparably short periods of time allows researchers to investigate the within-person processes through which job demands and job resources impact work outcomes in daily working life.

Researchers in work and organizational psychology have investigated many kinds of within-person processes using diary study designs. Initially, research focused on the interplay between work and leisure time recovery (e.g., Sonnentag, 2001; Sonnentag \& Bayer, 2005), which sparked streams of research focused on the effects of different recovery activities (Sonnentag \& Fritz, 2007) and the role of psychological detachment for leisure time recovery (Sonnentag \& Fritz, 2015). Despite the undisputed importance of research on psychological detachment and recovery during leisure time, the present chapter will focus on more immediate 
within-person processes that take place during the workday as work is carried out. Drawing on action regulation theory (e.g., Frese \& Zapf, 1994), the transactional theory of stress (e.g., Lazarus \& Folkman, 1984), and self-determination theory (Ryan \& Deci, 2000) as well as recent diary studies based on these theories, the following subsections of this chapter will give an overview of the within-person processes of action regulation, cognitive appraisal, and motivation.

\section{Action regulation processes: Goal-oriented behavior and self-control effort}

Action regulation theory (e.g., Frese \& Zapf, 1994; Hacker, 2003) describes withinperson processes that guide work behavior. It defines action as goal-oriented behavior that can be regulated consciously or via routines and describes the action process across different levels of action regulation (Frese \& Zapf, 1994, p. 271).

At the beginning of the action process, work tasks that are assigned by the organization are usually translated into work goals. The translation of work tasks into work goals usually involves a process of redefinition (Hackman, 1970), which is influenced by a number of factors, like the employee's understanding of the external task and its clarity. The resulting work goals can be described as anticipated future results that help guide the action process (Frese \& Zapf, 1994). In the next steps of the action process, employees generate action plans that take their evaluation of the environment into account and decide which action program to enact. Although the action programs generated may be more or less detailed, they are usually broken down into lower-level sub-programs that often relate to sub-goals of the more general work goal being pursued (Hacker, 2003; Frese \& Zapf, 1994).

During the execution of the action programs and their sub-programs, employees use feedback to repeatedly compare their performance to the respective goals or sub-goals in order to assess their progress. The feedback used to monitor the execution of work programs can take many forms. For lower-level sub-programs, feedback often originates from the action itself or is available externally in the form of signals (e.g., error messages), whereas for higher-level 
programs feedback is also often provided by supervisors or co-workers. Once the feedback tells an employee that a certain sub-goal has been achieved, the employee will turn to the next subprogram and try to make progress on the next sub-goal (Hacker, 2003; Frese \& Zapf, 1994).

Although goals are formed at a conscious level, they do not necessarily stay in consciousness over the entire action process. Instead, they are often only brought back into consciousness when (sub-)programs do not lead to the achievement of their associated (sub-)goals. Actions themselves can be regulated at three levels that differ in their requirements in terms of cognitive processing and effort (cf. Hacker, 2003; Frese \& Zapf, 1994; for examples see also Zapf, 2002). At the intellectual level of action regulation, action programs are designed for new work goals respectively adapted when they do not result in the achievement of the goals associated with them (e.g., because of changes in environmental conditions). At this level, processing consists of conscious problem solving and decisions to generate new strategies and plans. As a consequence, action regulation at the intellectual level is rather slow and resourceintensive compared to action regulation at other levels. At the knowledge-based level, employees rely on previously generated action programs, which are triggered by well-trained situational cues and signals. As a consequence, action regulation at this level makes use of flexible action patterns that do not necessarily require conscious control of one's actions. At the routine or sensorimotor level of regulation, automatic movement sequences are performed without conscious attention. As a consequence, action programs that are regulated at the routine or sensorimotor level are very hard to consciously modify when necessary (Frese \& Zapf, 1994).

For example, if an employee is assigned a new goal to create some sort of report, she or he will first have to make decisions about how to break this task into subtasks (e.g., research up-to-date numbers, process them, write the report) and plan which tools she/he will use (e.g., whether to use a spreadsheet application or a statistical application to process the numbers). Throughout the execution of these plans, the employee will have to monitor her/his progress 
and adapt her/his plans if necessary. These forms of regulations would most likely take place at the intellectual level, requiring high levels of cognitive processing. During the execution of her or his plans, the employee might, however, also encounter situations that allow for regulation at the knowledge-based and/or the routine or sensorimotor levels. While preparing the data, the employee might realize that some data is only available in a specific format and has to be converted before it can be processed. If the employee has encountered such a situation before and already knows a way to deal with it, regulation will take place on the knowledgebased level, requiring fewer cognitive resources. Similarly, the employee might discover that some of the data is only available in printed form and thus has to be entered into the computer manually. If the employee already has a lot of experience with data entry, regulation can proceed on the routine or sensorimotor level, requiring very few cognitive resources.

Action regulation theory not only elegantly describes the processes involved in the regulation of work tasks (translating tasks into goals, generating action plans, monitoring action, and processing feedback) but also provides an excellent explanation of how work stressors lead to work strain through increased taxation on employees' mental resources for the regulation of action processes.

Based on action regulation theory (e.g., Zapf, 2002), task characteristics can be divided into three groups: regulation requirements, regulation possibilities, and regulation problems. Regulation requirements refer to task characteristics like task variety and task complexity. Highly complex tasks require more regulation at the intellectual level than tasks that are less complex, highly routinized, or have been the subject of extensive training. Regulation possibilities include various aspects of how employees can exert control over the work situation like the order and timing in which operations are performed. Finally, regulation problems subsume various forms of work stressors that interfere with and disturb action regulation processes. Regulation problems include, for example, interruptions (because they obstruct action regulation), qualitative overload (because it creates uncertainty in regulation processes), 
as well as time pressure and other demands that overtax employees' capacity for action regulation (Frese \& Zapf, 1994). Well-designed jobs are not only characterized by low levels of work stressors that pose regulation problems and lead to health impairment, but also involve adequate levels of regulation requirements and regulation possibilities that provide employees with opportunities for learning and personality development (Glaser, Seubert, Hornung, \& Herbig, 2015).

Building on these theoretical assumptions of how work stressors are linked to indicators of job strain, Diestel and Schmidt (2012) proposed and demonstrated that regulation problems (high levels of qualitative and quantitative workload) trigger resource-depleting self-regulatory processes. By integrating action regulation theory with the self-control strength model (e.g., Baumeister, Vohs, \& Tice, 2007), Diestel and Schmidt (2012) showed that coping with high levels of qualitative and quantitative workload requires employees to inhibit impulsive response tendencies, ignore task-irrelevant stimuli, and overcome motivational deficits to complete unattractive tasks. These cognitive processes, which are a requirement for action regulation, have previously been shown to draw on and deplete limited cognitive resources for selfregulation (Hagger, Wood, Stiff, \& Chatzisarantis, 2010).

Further evidence that regulation problems do indeed express their adverse effects on employee well-being by overtaxing employees' resources for action regulation comes from a recent diary study showing that not only high workload or time pressure but also emotional dissonance triggers resource-depleting self-regulatory processes that require increased selfcontrol effort (Prem, Kubicek, Diestel, \& Korunka, 2016). This shows that the hypothesized adverse effects also extend to regulation problems other than high levels of workload. However, in our diary study, my colleagues and I also showed that regulation problems trigger anxiety and that the link between regulation problems and increased self-control effort can in part be explained via these increased levels of anxiety in employees faced with regulatory problems. This indicates that it is important to also consider the emotions triggered in cognitive appraisal 
processes in order to get a more comprehensive picture of the immediate within-person processes that take place during the workday.

\section{Cognitive appraisal processes: Appraisals and emotions}

In contrast to action regulation theory, which has a strong focus on the mental processes underlying goal-oriented work behavior but leaves the individual's subjective perception of the work situation deliberately aside (cf. Frese \& Zapf, 1999), other theories highlight the role of subjective evaluations in stress processes because of their impact on emotions and coping behavior. Most of these theories draw on the transactional model of stress (Lazarus \& Folkman, 1984) to explain the role of cognitive appraisal processes in work settings.

The transactional model of stress (Lazarus \& Folkman, 1984) describes coping behavior as a function of cognitive appraisal processes. In what is known as primary appraisal, the individual evaluates whether there is something at stake in the situation ("Am I in trouble or being benefited, now or in the future, and in what way?", Lazarus \& Folkman, 1984, p. 31). A situation can be appraised as irrelevant if it does not affect the individual's well-being, as benign-positive if it preserves or enhances the individual's well-being, or as stressful if it has the potential to negatively affect the individual's well-being. If the situation is appraised as stressful, one can distinguish the stress appraisal further into situations where harm or loss has already occurred and situations that pose a threat and/or challenge for the future. Whether the situation is perceived as having only negative effects in the future (threat appraisal) or whether it also has the potential for gain and growth (challenge appraisal) will affect the individual's emotions. In the case of threat appraisals, people are more likely to experience negative emotions such as fear, anxiety, and anger, whereas in the case of challenge appraisal, positive emotions like eagerness, excitement, and exhilaration will dominate.

During secondary appraisal, the individual will evaluate her or his coping options (“What if anything can be done about it?", Lazarus \& Folkman, 1984, p. 31). In this cognitive process, the individual not only evaluates which coping options she/he has available but also 
her/his likelihood of being able to execute the coping behavior and the likelihood that the coping behavior leads to the desired outcome. Although the terms primary appraisal and secondary appraisal seem to suggest a chronological order, the two types of cognitive appraisal are presumed to take place in parallel and influence one another. For example, if the available coping options are evaluated as presumably ineffective against an expected harm or loss, the individual will appraise the situation as a threat, whereas if one considers the situation to be controllable, she or he is also more likely to appraise it as a challenge. The cognitive appraisal of a situation will not only elicit certain emotions but also influence coping behavior. Problemfocused coping that aims to directly attack the stressor is more likely when the individual perceives control over the situation, whereas other situations, especially those in which the individual perceives negative emotions, will trigger emotion-focused coping behavior that aims to alter the interpretation of the stressor (see also Lazarus, 1995).

The idea that individuals' cognitive appraisal of a situation affects how they deal with stressful situations has also influenced work psychology. In the challenge stressors-hindrance stressors literature (Cavanough, Boswell, Roehling, \& Boudreau, 2000; LePine, Podsakoff, \& LePine, 2005), scholars distinguish between challenge stressors that have the potential to motivate employees and hindrance stressors that lack equivalent positive effects. Although both types of stressors require effort and thus draw on and deplete employees' resources, challenge stressors like time pressure and responsibility are thought to also have positive effects that stem from feelings of accomplishment and growth when these stressors are met successfully. In contrast, overcoming hindrance stressors like role ambiguity and red tape does not typically provide such positive experiences. Consequently, hindrance stressors do not promote motivation and are only related to indicators of job strain (e.g., LePine et al., 2005, Crawford, LePine, \& Rich, 2010; Van den Broeck, De Cuyper, De Witte, \& Vansteenkiste, 2010). 
In recent years, research based on the challenge stressors-hindrance stressors framework has not only classified stressors as challenge or hindrance stressors based on their effects but has also begun to measure cognitive appraisal directly (Webster, Beehr, \& Love, 2011). Diary studies have shown that challenge stressors are indeed more strongly related to challenge appraisal than hindrance appraisal and that hindrance stressors are only related to hindrance appraisal, not challenge appraisal (Searle \& Auton, 2015). Furthermore, it has been shown that challenge stressors are linked to activated positive affect via challenge appraisal and that hindrance stressors are linked to anger via hindrance appraisal (Searle \& Auton, 2015). Other diary studies have demonstrated that not only job demands like time pressure but also job resources like job control or positive meaning have positive effects on work outcomes like creativity, proactive work behavior, and learning at work via challenge appraisal (Ohly \& Fritz, 2010; Prem, Ohly, Kubicek, \& Korunka, in press). Finally, it has recently been shown that it makes sense to not only measure challenge appraisal and hindrance appraisal but also to distinguish between hindrance appraisals and threat appraisals. Tuckey, Searle, Boyd, Winefield, and Winefield (2015) showed in a diary study that stressors that obstruct accomplishment promote fatigue via hindrance appraisal, whereas stressors related to harm to the self or personal loss lead to anger and anxiety via threat appraisals. Overall, empirical evidence suggests that cognitive appraisal processes are useful in explaining within-person relationships between work characteristics, emotions and performance-related outcomes.

\section{Motivational processes: Basic need satisfaction and work motivation quality}

An overview of the within-person processes that underlie goal-oriented work behavior would not be complete without also considering motivational processes. To get a more comprehensive picture of day-level within-person processes and complement action regulation theory, which focuses on how work tasks are mentally regulated, and the transactional stress model, which explains how employees' appraisal of their work situation impacts their emotions 
and coping strategies, I will draw on self-determination theory (e.g., Ryan \& Deci, 2000) to describe the determinants of different kinds of motivation at work.

Self-determination theory (e.g., Ryan \& Deci, 2000; see also Gagné \& Deci, 2005) views motivation quality on a continuum from amotivation to various forms of extrinsic motivation and finally to intrinsic motivation. In contrast to intrinsic motivation, where behavior is driven by interest in and enjoyment of the task itself, extrinsically motivated behavior is pursued for different reasons. In the case of extrinsic motivation, individuals may regulate their behavior simply to attain external rewards or to avoid external punishments (external regulation). In such cases, the individual will only perform actions if she or he expects them to be instrumental in obtaining desired rewards and/or avoiding undesired consequences. For example, an employee might only work if she or he is being monitored by her/his supervisor. However, extrinsic motivation can also be internalized to various degrees. In the case of introjected regulation, employees typically perform their work tasks because they feel pressure to attain set goals to maintain their self-esteem. In contrast, in the case of identified regulation, employees perform a behavior because it is in line with their personal goals and identities. Finally, the most internalized form of external motivation is integrated regulation, which occurs when employees see their behavior as an integral part of themselves (Gagné \& Deci, 2005).

Although identified regulation and integrated regulation are still forms of external motivation (because they are pursued to attain personal goals), they also share some similarities with intrinsic motivation. As a consequence, identified regulation and integrated regulation are often combined with intrinsic motivation to form a composite known as autonomous motivation, which is then distinguished from external regulation and introjected regulation, which are combined to a composite known as controlled motivation (Gagné \& Deci, 2005).

The degree to which a given behavior is internalized is thought to be influenced by aspects of the social context and, in particular, by the satisfaction of basic psychological needs 
it provides (Ryan \& Deci, 2000). Self-determination theory argues that the satisfaction of needs for relatedness, competence, and autonomy acts as a nutriment for autonomous motivation (e.g., Gagné \& Deci, 2005). Internalization of externally motivated behaviors is fostered when an individual feels a sense of belonging and connectedness with others (relatedness), experiences efficacy with regard to the behavior (competence), and has a sense of choice and freedom (autonomy). In work settings, these factors might not only be influenced by aspects of the job content and context, but also by a work climate that can be described as autonomy supportive. Managers can foster a climate supportive of autonomy by giving their employees opportunities to take initiative and make choices at work, by providing them with non-controlling informal feedback and by recognizing their needs and feelings (Gagné \& Deci, 2005; see also Van den Broeck, Vansteenkiste, \& De Witte, 2008). However, if basic psychological needs are frustrated rather than satisfied, this will be detrimental to the internalization of behaviors and foster controlled motivation instead of autonomous motivation.

It has been assumed that autonomous motivation should have effects on both employees' well-being and their performance (Gagné \& Deci, 2005). Empirical studies have confirmed that need satisfaction partially mediates between job demands and job resources and indicators of employee well-being like vigor and exhaustion (Van den Broeck, Vansteenkiste, De Witte, \& Lens, 2008). Further, it has been shown that job demands increase controlled motivation via need frustration and that job resources decrease controlled motivation by lowering need frustration and increase autonomous motivation via need satisfaction (Trépanier, Forest, Fernet, \& Austin, 2015). Controlled motivation has been linked to more psychological distress, more psychosomatic complaints, lower work engagement, and lower job performance, whereas autonomous motivation has been shown to be associated with higher work engagement and better job performance (Trépanier et al., 2015). Need frustration has also been used to explain the adverse effects of job insecurity on emotional exhaustion and vigor (Vander Elst, Van den Broeck, De Witte, \& De Cuyper, 2012) as well as counterproductive work behavior 
from both an organizational and interpersonal perspective (Van den Broeck, Sulea, Iliescu, \& De Witte, 2014). Regarding within-person processes, diary studies have shown that withinperson processes serially link need satisfaction to vigor and fatigue via increased intrinsic work motivation and subsequently reduced self-control effort (Van Hooff \& Geurts, 2015). Overall, empirical evidence seems to support the assumption that basic need satisfaction and/or basic need frustration affect employees' well-being and performance via autonomous motivation and/or controlled motivation. Moreover, results from diary studies suggest that these processes are also linked to self-control effort.

\section{The interplay of within-person processes in daily working life}

Action regulation processes, cognitive appraisal processes, and motivational processes unfold simultaneously and influence one another in daily working life. In the following section, I will try to integrate these processes in a framework model to draw a more complete picture of the interplay of the within-person processes that impact employees' well-being and performance. Integrating these three different processes requires me to reduce some complexity, and thus I will sacrifice some accuracy and richness of the theories that I draw upon to obtain a reasonably simple framework model.

\section{[Figure 1]}

As depicted in Figure 1, I chose to classify work characteristics into hindrance demands, challenge demands, and job resources based on the challenge stressor-hindrance stressor literature (cf. Crawford et al., 2010)[Footnote 1]. Based on action regulation theory (e.g., Frese \& Zapf, 1994), I assume that both hindrance demands and challenge demands will trigger action regulation processes because they ought to pose regulation requirements and/or regulation problems. Job resources will act as regulation possibilities and thus facilitate action regulation processes. Action regulation processes, in turn, are thought to require self-control effort (e.g., Diestel \& Schmidt, 2012) and thus draw on and deplete employees' mental resources. As a consequence, self-control effort will negatively affect both employees' well-being and their 
performance. However, action regulation processes might also foster personality development and thus lead to learning, which could have positive effects on employees' well-being and performance in the long run.

From the challenge stressors-hindrance stressors literature (e.g., Searle \& Auton, 2015, Tuckey et al., 2015), it can be assumed that hindrance demands promote hindrance and/or threat appraisals that in turn increase negative emotions and/or negative affect. Because negative emotions entrain action tendencies that lead to withdrawal and/or aggressive behavior, employees will have to invest self-control effort to overcome these action tendencies (e.g., Mackey \& Perrewé, 2014). Challenge demands should promote both challenge appraisals and hindrance appraisals (e.g., Webster et al., 2011; Searle \& Auton, 2015, Prem et al., in press). Via their effects on challenge appraisal, challenge demands should increase positive affect, which might provide employees not only with energy that can be invested in self-control effort but also broaden their thought-action repertoire (Frederickson, 2001), promoting creativity, development, and learning at work (Prem et al., in press). Because job resources help employees cope with their hindrance and challenge demands, job resources should lead to more challenge appraisals and fewer hindrance appraisals (e.g., Ohly \& Fritz, 2010; Paškvan, Kubicek, Prem, \& Korunka, 2016; Prem et al., in press), thus reducing self-control effort and boosting learning at work.

Finally, according to self-determination theory (e.g., Ryan \& Deci, 2000; Gagné \& Deci, 2005), hindrance demands should frustrate basic psychological needs and thus have negative effects on need satisfaction, while challenge demands and job resources should provide opportunities for need satisfaction (cf. Van den Broeck, De Cuyper, De Witte, \& Vansteenkiste, 2010; Albrecht, 2015). Need satisfaction should in turn lead to more autonomous motivation, which should decrease self-control effort (cf. Van Hooff \& Geurts, 2015) and promote employees' learning at work (Spreitzer \& Porath, 2014). 
In my framework model (cf. Figure 1), self-control effort and learning take central roles in combining the effects of action regulation processes, cognitive appraisal processes, and motivational processes. It is assumed that adverse effects on employees' health and performance will mainly be explained via self-control effort and beneficial effects on employees' health and performance will mainly be explained via learning at work.

By containing both adverse as well as beneficial indirect effects on work outcomes, the framework model shares some similarity with other models of job stress that differentiate between (adverse) strain-related processes and (beneficial) motivational processes (e.g., Bakker \& Demerouti, 2007; Glaser et al., 2015; LePine et al., 2005). Because the effects via self-control effort and learning at work often antagonize each other, the overall effect of work characteristics on work outcomes will be ambivalent and the result in the long run will depend on whether the adverse effects outweigh the beneficial effects or vice versa.

It should be mentioned that I do not assume that self-control effort and learning at work will be able to completely explain the effects of hindrance demands, challenge demands, and job resources on employees' well-being and performance. Nevertheless, self-control effort and learning at work have a prominent role in the framework model because they link within-person processes of action regulation, cognitive appraisal, and motivation.

\section{The Effects of Changing Work Environments on Within-person Processes}

In the following section, I will reflect on how changes in modern work environments might affect the previously described within-person processes of action regulation, cognitive appraisal, and motivation in daily working life. At first glance, it may seem counterintuitive that changes in work environments (that oftentimes unfold over relatively long periods of time) can have an impact on processes that unfold from day to day (within rather short periods of time). However, some earlier theories of work stress have already made assumptions about how chronic work characteristics might affect within-person stress processes and vice versa. For example, the allostatic load model (McEwen, 2007) explains how biological processes of short- 
term stress responses lead to more chronic changes that alter the homeostasis in endocrinal and neuronal mechanisms and how such adaptation processes can affect future short-term stress responses. Largely on the basis of McEwen's model, Ilies and colleagues called for researchers to investigate the interaction of short-term and chronic effects in naturalistic settings and to develop other comprehensive theoretical models integrating the perspectives of short-term and chronic effects (Ilies, Aw, \& Lim, 2016; Ilies, Aw, \& Pluut, 2015).

To explain how changes in work environments affect short-term within-person processes, I will add another layer of complexity and differentiate between (a) long-term changes in work environments that affect both (b) chronic working conditions and (c) day-level within-person processes. Changing work environments should alter chronic work characteristics over time. As a consequence, long-term changes in the work environment may affect day-level within-person processes via their effects on chronic work characteristics. For example, work intensification may lead to more chronic workload over time, which may influence how employees cope with daily time pressure. However, it is also plausible that not all effects of changing work environments on day-level within-person processes are mediated through chronic work characteristics. For example, work intensification might not only affect how employees cope with daily time pressure because it leads to higher chronic workload, but also more directly, because employees experiencing work intensification might develop a more negative attitude towards workload and time pressure as a consequence of work intensification. In other words, changes in the work environment may not only affect day-level within-person processes because they alter the quantitative level of chronic work characteristics but also because they might alter the appraisal of work characteristics.

\section{Effects of changing work environments on action regulation processes}

Changes in modern work settings may affect the action regulation process in various ways. First, if chronic work characteristics change, regulation demands may increase and, if they exceed certain levels, also pose additional regulation problems. For example, work 
intensification increases chronic workload and consequently also daily time pressure. If employees have to work faster than usual, their capacity for action regulation might be overtaxed, meaning that additional self-control effort is required. Of course, it should be mentioned that changes in work environments do not necessarily have only adverse effects. For example, redesigning traditional office spaces into activity-based flexible office spaces might also reduce noise and interruptions and thus reduce regulation problems.

Second, frequent changes in the way work is organized and/or the technical equipment used to carry out work will require employees to update action plans or generate new ones more often. This will increase action regulation processes that unfold at the intellectual level. As a consequence, employees will be less able to rely on regulation processes at the knowledgebased level and/or the routine or sensorimotor level. Because they are less able to rely on routines, additional self-control effort will again be required from employees. However, increased regulation at the intellectual level might also provide opportunities for development and learning at work.

Third, some changes in the work environment will require employees to not only regulate goal-oriented work behavior, but also to get involved in other self-regulation processes. For example, as work becomes more flexible with respect to where and when employees engage in their work, employees will have to plan how they organize their work tasks during working hours but also the times at which they work and when they perform chores or spend time with their family, etc. Although such forms of flexibility provide employees with opportunities to adapt their work schedule to non-work needs, the self-regulation processes involved in planning not only one's actions at work but also when and where to work require additional mental resources. Similarly, if career paths become less stable and employees have to take care of their own development and future employment opportunities, employees will have to invest additional resources not only in making plans for their career but also in pursuing these plans. 
Finally, some work characteristics that are usually regarded as resources for regulation might acquire the quality of regulation requirements. For example, having control over the order in which one performs individual work tasks and the means one uses to do so are usually regarded as resources that ease action regulation processes. However, if such work characteristics are combined with high performance goals and no clear structure of how to obtain these goals, they may no longer provide employees with freedom in their work. Instead, employees might be left only with increased qualitative demands that require additional selfcontrol effort in goal-oriented work behavior.

\section{Effects of changing work environments on cognitive appraisal processes}

Changes in modern work settings may also affect cognitive appraisal processes in multiple ways. First, changes in the extent of hindrance demands should have effects on the extent to which employees appraise their work situations as hindrances and/or threats. If organizations reduce bureaucracy, employees might experience less red tape, which should also reduce hindrance appraisals as well as experiences of negative emotions and negative affect. At the same time, if competences are less clearly defined, hindrance stressors like role ambiguity might increase, which could lead employees to perceive their work situation as more hindering. Similarly, increases in job insecurity might boost threat appraisals in employees, accompanied by feelings of anger and/or anxiety.

Second, changes in the extent of challenge demands should have effects on challenge appraisals. Increases in time pressure and responsibility should theoretically facilitate challenge appraisals as well as positive emotions and positive affect. As a consequence, increasing challenge demands might provide employees with opportunities for learning and growth at work. However, it should be highlighted that challenge demands can also be appraised as hindrances. In particular, if time pressure reaches a level where employees no longer expect to be able to attain their goals, they should be more likely to appraise their work situations as a hindrance and/or threat, which goes along with negative emotions and negative affect. 
Finally, because job resources play an important role in secondary appraisal processes when employees evaluate their coping options, the availability of job resources should also impact challenge appraisals, hindrance appraisals, and/or threat appraisals. In particular, job resources should boost challenge appraisals and extenuate hindrance and/or threat appraisals.

\section{Effects of changing work environments on motivational processes}

In addition to their potential effects on action regulation processes and cognitive appraisal processes, changes in modern work settings should also impact motivational processes. Changes in working conditions may affect the extent to which basic needs are satisfied and/or frustrated, which in turn affect the quality of motivation.

On the one hand, the frustration of basic psychological needs should lead to more controlled motivation, which goes along with increased self-control effort and less learning at work. For example, when facing increasing levels of workload due to work intensification, employees may no longer be able to attain their work goals and consequently cease to experience feelings of competence. As a consequence, they will experience less autonomous motivation and more controlled motivation. This ultimately means that these employees will have to invest additional self-control effort to force themselves to work.

On the other hand, modern work settings may also aid in the satisfaction of basic psychological needs. This promotes more autonomous motivation, which should reduce selfcontrol effort and provide a climate for learning at work. For example, flexible work times that give employees true freedom over when they work could help satisfy employees' need for autonomy and consequently lead to autonomous motivation. Similarly, if a worker decides to switch to a job or profession that is more in line with their personal goals and identities, they may also be more autonomously motivated at work. 


\section{Ambivalent Consequences of Changing Work Environments in Daily Working Life}

As we have seen in the previous chapters, societal, economic, and technological changes affect modern work settings. This may result in both adverse and beneficial effects on work outcomes like employee well-being and performance in daily working life.

Changes that lead to regulation problems, promote hindrance or threat appraisals, and/or frustrate basic psychological needs will likely require employees to invest additional selfcontrol effort at work. Because the investment of self-control effort draws on and depletes employees' limited resources for self-regulation, this will have adverse effects on employees' job strain. Longitudinal studies have shown that demands to invest self-control effort at work are related to indicators of burnout like emotional exhaustion and depersonalization (Diestel \& Schmidt, 2012). Further, diary studies have also linked requirements to invest self-control effort to increased need for recovery and ego depletion as well as decreased work engagement (Rivkin, Diestel, \& Schmidt, 2015; Prem et al., 2016). It can be assumed that if employees are not able to sufficiently recover the resources they invest in additional self-control effort, it will not only have effects on well-being but also affect their work performance. For example, if employees' self-regulatory resources are depleted, they may be more likely to procrastinate on their work tasks (Kühnel, Bledow, \& Feuerhahn, 2016) and may also lack the energy to be proactive (Parker, Bindl, \& Strauss, 2010).

Changes that foster regulation requirements, promote challenge appraisals, and/or satisfy basic psychological needs will likely also provide employees with opportunities for learning and growth. Research on employees' thriving at work has shown that employees who experience both vitality as well as a sense of learning and personal growth at work not only score lower on burnout indicators but are also more likely to be satisfied with their job and committed to their organizations (Porath, Spreitzer, Gibson, \& Garnett, 2012). Furthermore, thriving employees are also more proactive at work, show more initiative in their career development, and attain better job performance (Porath et al., 2012). However, it should be 
highlighted that to experience thriving at work, it is not sufficient to experience just a sense of learning and personal growth at work. Instead, thriving individuals also have to experience vitality, which can be described as a sense of aliveness (cf. Spreitzer, Sutcliffe, Dutton, Sonenshein, \& Grant, 2005). Thus, employees will not be able to thrive on learning opportunities if their mental resources are drained by the self-control effort they have to put into their work.

Although some changes, like work intensification, may have mainly adverse consequences on work outcomes, other changes, like those related to flexible working, may also hold the potential for beneficial effects. Overall, one can assume that many societal, economic, and technological changes may have ambivalent consequences on within-person processes of action regulation, cognitive appraisal, and motivation as well as on work outcomes that result from these processes.

\section{Conclusion}

In this chapter I gave an overview of various within-person processes that link work characteristics to work outcomes in daily working life. Drawing on action regulation theory (e.g., Frese \& Zapf, 1994; Hacker, 2003), the transactional stress model (Lazarus \& Folkman, 1984; Searle \& Auton, 2015), as well as self-determination theory (Ryan \& Deci, 2000; Gangné \& Deci, 2005), I tried to explain how changes in modern work settings affect within-person processes in daily working life.

Because societal, economic, and technological changes may have both adverse and beneficial effects on employees' well-being and performance, one might conclude that is not yet clear whether these changes will be more of a blessing or a curse for employees in the future. Although this might be true in some cases, like flexible working arrangements (Gerdenitsch, Kubicek, \& Korunka, 2015), there is also some evidence suggesting that a few changes are clearly negative. For example, it has been shown that workers appraise work intensification as a hindrance (Paškvan et al., 2016). To predict how changes in work settings affect work 
outcomes, it may thus make sense to consider their effects on within-person processes in daily working life.

I recommend that future research not only tries to further integrate theories about various within-person processes but also consider how these processes might interact on the short-, medium-, and long-term levels. In my opinion, it is important to empirically analyze how changes in modern work settings affect chronic work characteristics and how these changes affect within-person processes in daily working life (see also Ilies et al., 2015, 2016).

The changes in today's world of work pose challenges for companies. In order to stay competitive, companies have to adapt quickly to societal, economic, and technological changes in the work environment. However, it is also becoming increasingly important for companies to maintain a thriving workforce that is energized, grows and develops to be sustainable (Spreitzer, Porath, \& Gibson, 2012). Thus, it is necessary to actively create working conditions that enable employees to stay both healthy and productive. Creating work climates supportive of autonomy and ensuring that employees have sufficient opportunities to recharge their energy and stay vital could be key to fostering the conditions that allow both employees and their companies to thrive.

Finally, I would like to remind practitioners it is upon them to actively design tomorrow's work environments. Although practitioners may consider themselves constrained in how they can react to the effects of societal, economic, and technological changes on work settings, they should focus on how to buffer the adverse effects of such changes through work redesign while also keeping an eye on how to utilize potential beneficial effects. Employees should be given opportunities to craft their jobs and/or their careers to match their needs. These efforts should be backed by legislation that emphasizes the importance of healthy work environments. In the end, well-designed jobs will not only benefit employees themselves but also the companies they work for and society as a whole. 


\section{References}

Albrecht, S. L. (2015). Challenge demands, Hindrance demands, and psychological need satisfaction. Journal of Personnel Psychology, 14, 70-79.

Bakker, A. B., \& Demerouti, E. (2007). The job demands-resources model: State of the art. Journal of Managerial Psychology, 22, 309-328.

Baumeister, R. F., Vohs, K. D., \& Tice, D. M. (2007). The strength model of self-control. Current Directions in Psychological Science, 16, 351-355.

Bolger, N., Davis, A., \& Rafaeli, E. (2003). Diary methods: Capturing life as it is lived. Annual Review of Psychology, 54, 579-616.

Cascio, W. F. (1995). Whither industrial and organizational psychology in a changing world of work? American Psychologist, 50, 928-939.

Cavanaugh, M. A., Boswell, W. R., Roehling, M. V., \& Boudreau, J. W. (2000). An empirical examination of self-reported work stress among US managers. Journal of Applied Psychology, 85, 65-74.

Crawford, E. R., LePine, J. A., \& Rich, B. L. (2010). Linking job demands and resources to employee engagement and burnout: A theoretical extension and meta-analytic test. Journal of Applied Psychology, 95, 834-848.

Diestel, S., \& Schmidt, K.-H. (2012). Lagged mediator effects of self-control demands on psychological strain and absenteeism. Journal of Occupational and Organizational Psychology, 85, 556-578.

Fisher, C. D., \& To, M. L. (2012). Using experience sampling methodology in organizational behavior. Journal of Organizational Behavior, 33, 865-877.

Frese, M., \& Zapf, D. (1994). Action as the core of work psychology: A German approach. In H. C. Triandis, M. D. Dunnette, \& L. M. Hough (Eds.), Handbook of Industrial and Organizational Psychology (Vol. 4., pp. 271-340). Palo Alto, CA: Consulting Psychologists Press. 
Gagné, M., \& Deci, E. L. (2005). Self-determination theory and work motivation. Journal of Organizational Behavior, 26, 331-362.

Gerdenitsch, C., Kubicek, B., \& Korunka, C. (2015). Control in flexible working arrangements: When freedom becomes duty. Journal of Personnel Psychology, 14, 6169.

Glaser, J., Seubert, C., Hornung, S., \& Herbig, B. (2015). The impact of learning demands, work-related resources, and job stressors on creative performance and health. Journal of Personnel Psychology, 14, 37-48.

Hacker, W. (2003). Action Regulation Theory: A practical tool for the design of modern work processes? European Journal of Work and Organizational Psychology, 12, 105-130.

Hackman, J. R. (1970). Tasks and task performance in research on stress. In J. E. McGrath (Ed.), Social and Psychological Factors in Stress (pp. 202-237). New York, NY: Holt, Rinehart \& Winston.

Hagger, M. S., Wood, C., Stiff, C., \& Chatzisarantis, N. L. (2010). Ego depletion and the strength model of self-control: A meta-analysis. Psychological Bulletin, 136, 495-525.

Ilies, R., Aw, S. S., \& Lim, V. K. (2016). A naturalistic multilevel framework for studying transient and chronic effects of psychosocial work stressors on employee health and well-being. Applied Psychology, 65, 223-258.

Ilies, R., Aw, S. S., \& Pluut, H. (2015). Intraindividual models of employee well-being: What have we learned and where do we go from here? European Journal of Work and Organizational Psychology, 24, 827-838.

Kubicek, B., Paškvan, M., \& Korunka, C. (2015). Development and validation of an instrument for assessing job stressors arising from accelerated change. The Intensification of Job demands Scale (IDS). European Journal of Work and Organizational Psychology, 24, 898-913. 
Kühnel, J., Bledow, R., \& Feuerhahn, N. (2016). When do you procrastinate? Sleep quality and social sleep lag jointly predict self-regulatory failure at work. Journal of Organizational Behavior, 37, 983 -1002.

Lazarus, R. S. (1995). Psychological stress in the workplace. In R. Crandall \& P. L. Perrewé (Eds.), Occupational stress: A handbook (pp. 3-19). Washington, DC: Taylor \& Francis.

Lazarus, R. S. \& Folkman, S. (1984). Stress, appraisal, and coping. New York, NY: Springer.

LePine, J. A., Podsakoff, N. P., \& LePine, M. A. (2005). A meta-analytic test of the challenge stressor-hindrance stressor framework: An explanation for inconsistent relationships among stressors and performance. Academy of Management Journal, 48, 764-775.

Mackey, J. D., \& Perrewé, P. L. (2014). The AAA (appraisals, attributions, adaptation) model of job stress: The critical role of self-regulation. Organizational Psychology Review, 4, $258-278$.

McEwen, B. S. (2007). Physiology and neurobiology of stress and adaptation: Central role of the brain. Physiological Reviews, 87, 873-904.

Ohly, S., \& Fritz, C. (2010). Work characteristics, challenge appraisal, creativity, and proactive behavior: A multi-level study. Journal of Organizational Behavior, 31, 543-565.

Ohly, S., Sonnentag, S., Niessen, C. \& Zapf, D. (2010). Diary studies in organizational research: An introduction and some practical recommendations. Journal of Personnel Psychology, 9, 79-93.

Parker, S. K., Bindl, U. K., \& Strauss, K. (2010). Making things happen: A model of proactive motivation. Journal of Management, 36, 827-856.

Paškvan, M., Kubicek, B., Prem, R., \& Korunka, C. (2016). Cognitive appraisal of work intensification. International Journal of Stress Management, 23, 124-146. 
Porath, C., Spreitzer, G., Gibson, C., \& Garnett, F. G. (2012). Thriving at work: Toward its measurement, construct validation, and theoretical refinement. Journal of Organizational Behavior, 33, 250-275.

Prem, R., Kubicek, B., Diestel, S., \& Korunka, C. (2016). Regulatory job stressors and their within-person relationships with ego depletion: The roles of state anxiety, self-control effort, and job autonomy. Journal of Vocational Behavior, 92, 22-32.

Prem, R., Ohly, S., Kubicek, B., \& Korunka, C. (in press). Thriving on challenge stressors? Exploring time pressure and learning demands as antecedents of thriving at work. Journal of Organizational Behavior.

Rivkin, W., Diestel, S., \& Schmidt, K. H. (2015). Affective commitment as a moderator of the adverse relationships between day-specific self-control demands and psychological well-being. Journal of Vocational Behavior, 88, 185-194.

Rosa, H. (2003). Social acceleration: Ethical and political consequences of a desynchronized high-speed society. Constellations, 10, 3-33.

Rosa, H. (2013). Social acceleration: A new theory of modernity. New York, NY: Columbia University Press.

Ryan, R. M., \& Deci, E. L. (2000). Self-determination theory and the facilitation of intrinsic motivation, social development, and well-being. American Psychologist, 55, 68-78.

Searle, B. J., \& Auton, J. C. (2015). The merits of measuring challenge and hindrance appraisals. Anxiety, Stress, \& Coping, 28, 121-143.

Sonnentag, S. (2001). Work, recovery activities, and individual well-being: A diary study. Journal of Occupational Health Psychology, 6, 196-210.

Sonnentag, S., \& Bayer, U. V. (2005). Switching off mentally: Predictors and consequences of psychological detachment from work during off-job time. Journal of Occupational Health Psychology, 10, 393-414. 
Sonnentag, S., \& Fritz, C. (2007). The Recovery Experience Questionnaire: Development and validation of a measure for assessing recuperation and unwinding from work. Journal of Occupational Health Psychology, 12, 204-221.

Sonnentag, S., \& Fritz, C. (2015). Recovery from job stress: The stressor-detachment model as an integrative framework. Journal of Organizational Behavior, 36, S72-S103.

Spreitzer, G. M., \& Porath, C. (2014). Self-determination as nutriment for thriving: Building an integrative model of human growth at work. In M. Gagné (Ed.), Oxford handbook of work engagement, motivation, and self-determination theory (pp. 245-258). New York, NY: Oxford University Press.

Spreitzer, G., Porath, C. L., \& Gibson, C. B. (2012). Toward human sustainability: How to enable more thriving at work. Organizational Dynamics, 41, 155-162.

Spreitzer, G., Sutcliffe, K., Dutton, J., Sonenshein, S., \& Grant, A. M. (2005). A socially embedded model of thriving at work. Organization Science, 16, 537-549.

Trépanier, S. G., Forest, J., Fernet, C., \& Austin, S. (2015). On the psychological and motivational processes linking job characteristics to employee functioning: Insights from self-determination theory. Work \& Stress, 29, 286-305.

Tuckey, M. R., Searle, B. J., Boyd, C. M., Winefield, A. H., \& Winefield, H. R. (2015). Hindrances are not threats: Advancing the multidimensionality of work stress. Journal of Occupational Health Psychology, 20, 131-147.

Van den Broeck, A., De Cuyper, N., De Witte, H., \& Vansteenkiste, M. (2010). Not all job demands are equal: Differentiating job hindrances and job challenges in the Job Demands-Resources model. European Journal of Work and Organizational Psychology, 19, 735-759.

Van den Broeck, A., Vansteenkiste, M., De Witte, H., \& Lens, W. (2008). Explaining the relationships between job characteristics, burnout, and engagement: The role of basic psychological need satisfaction. Work \& Stress, 22, 277-294. 
Van den Broeck, A., Sulea, C., Vander Elst, T., Fischmann, G., Iliescu, D., \& De Witte, H. (2014). The mediating role of psychological needs in the relation between qualitative job insecurity and counterproductive work behavior. Career Development International, $19,526-547$.

Van Hooff, M. L. M., \& Geurts, S. A. E. (2015). Need satisfaction and employees' recovery state at work: A daily diary study. Journal of Occupational Health Psychology, 20, 377387.

Vander Elst, T., Van den Broeck, A., De Witte, H., \& De Cuyper, N. (2012). The mediating role of frustration of psychological needs in the relationship between job insecurity and work-related well-being. Work \& Stress, 26, 252-271.

Webster, J. R., Beehr, T. A., \& Love, K. (2011). Extending the challenge-hindrance model of occupational stress: The role of appraisal. Journal of Vocational Behavior, 79, 505516.

Zapf, D. (2002). Emotion work and psychological well-being: A review of the literature and some conceptual considerations. Human Resource Management Review, 12, 237-268. 


\section{Footnotes}

Footnote 1: I chose this classification of work characteristics because of its popularity in international work and organizational psychology literature. However, it should be mentioned that this classification does not fully overlap with action regulation theory. Although hindrance demands (e.g., red tape) are usually regarded as regulation problems, job resources (e.g., job autonomy) are considered regulation possibilities, and challenge demands can often be described as regulation requirements (e.g., responsibility), there are some exceptions to this rule of thumb. Most importantly, time pressure is regarded not as a regulation requirement but a regulation problem in action regulation theory. 


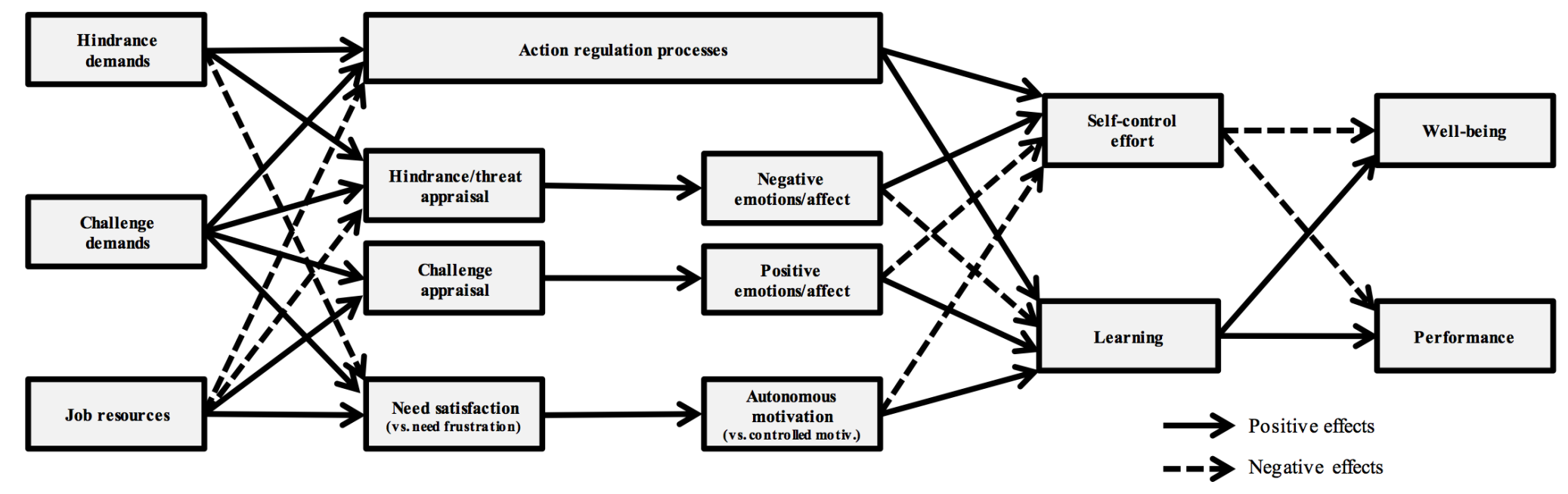

Figure 1. Framework model that integrates action regulation processes, cognitive appraisal processes, and motivational processes 